\title{
Small Molecular Sensing with Graphene, Zinc Oxide and Zinc Oxalate
}

\author{
$\mathrm{Hsu} \mathrm{C}{ }^{1 *}$ and $\mathrm{Xu} \mathrm{G}^{2}$ \\ ${ }^{1}$ Department of chemical and materials engineering, Lunghwa University of Science \\ and Technology, Taiwan \\ ${ }^{2}$ Gyizhou Institute of Technology, China
}

*Corresponding author: Chen Hsu, Department of chemical and materials engineering, Lunghwa University of Science and Technology, Taiwan, Email: chenhsuemail@yahoo.com.tw

\section{Editorial}

Volume 4 Issue 3

Received Date: November 25, 2019

Published Date: December 03, 2019

DOI: $10.23880 /$ nnoa-16000168

\section{Abstract}

Small molecules such as hydrogen and methane are able to be sensible using graphene, zinc oxide (ZnO), and zinc oxalate $\left(\mathrm{ZnC}_{2} \mathrm{O}_{4}\right)$ via Van der Waals force. The mini reviews mainly related to those materials with hydrogen are mainly concern. The crystals planes contain a large number of oxygen functional groups are crystal waters hidden in it play the important roles.

Keywords: Graphene; Zinc oxide; Zinc oxalate; $\beta-\mathrm{ZnC}_{2} \mathrm{O}_{4}$

\section{Editorial}

\section{Graphene}

Graphene is generally regarded as to have the function of adsorbing hydrogen molecules, but in really the adsorbing effect is not fit the demand. Strictly speaking, graphene has no the function of attracting hydrogen molecules. Graphene does not have the function of bullying hydrogen molecules. The main reason is that its plane is fully occupied by functional group. The graphene reduction exhibits many defect structures and residual oxidized groups, so even if many reduction methods are proposed, it is impossible to obtain a structure close to the perfect lattice of graphene. The basal plane and the edge of the reduced graphene oxide will contain a large number of oxygen functional groups; epoxy $(\mathrm{C}=0)$ and hydroxyl (hydroxyl, C) - $\mathrm{OH}$ is formed on the base surface, and carboxyl groups $(\mathrm{COOH})$ and carbonyl groups $(\mathrm{CO}$, CO) are distributed at the boundary [1].

\section{ZnO}

$\mathrm{ZnO}$ can be used to sensible small particles. Zinc oxide has a function of adsorbing hydrogen molecules, which is generally a plane occurring in the plane of $\left(001^{-}\right)$plane. The most common crystal structure of zinc oxide is hexagonal wurtzite. When the $\left(001^{-}\right)$plane is used as the surface, the crystal plane is composed of 0 atoms, which leads to the 0 atom with excess. The charge 0 - has surface activity. In theory, the $\mathrm{O}$ atoms on the surface have a strong ability to bind to $\mathrm{H}(\mathrm{H}+)$ atoms. The $\mathrm{O}$ atom is in an outwardly protruding position on the surface, and the steric hindrance is small when combined with the $\mathrm{H}$ atom, which is favorable for the reaction to proceed. The plane can also be attracted to the $\mathrm{CO}$ molecules, adsorbed on the $\left(001^{-}\right.$) crystal plane and the atoms interacting on the crystal plane are $\mathrm{H}$ atoms and $\mathrm{C}$ atoms [2-4].

\section{$\mathrm{ZnC}_{2} \mathbf{O}_{4}$}

Zinc oxalate has an open structure and rich coordination, so the structure can be designed and 


\section{Nanomedicine \& Nanotechnology Open Access}

modulated, and inorganic-inorganic and inorganicorganic composite materials are formed with inorganic and organic materials, and its function is determined by inorganic and organic functional group materials. So it shows potential application potential.

Many methods for preparing zinc oxalate. Zinc oxalate and oxalic acid are ground after heating to obtain zinc oxalate. Zinc oxalate can prepare oxalic acid. Zinc oxalate and oxalic acid are ground after heating to obtain zinc oxalate. Sodium dodecylbenzenesulfonate (DBS) was used as a template to prepare rod-shaped nanoscale $\mathrm{ZnC}_{2} \mathrm{O}_{4} \cdot 2 \mathrm{H}_{2} \mathrm{O}$ whiskers. Zinc sulfate heptahydrate Zinc nitrate heptahydrate Zinc chloride heptahydrate and oxalic acid to synthesize zinc oxalate dihydrate. Villous Zinc oxalate (Villous $\mathrm{ZnC}_{2} \mathrm{O}_{4}$ ) can be synthesized using the sol-gel and laser method from graphene and zinc oxide, such as, using high velocity laser process [5-7].

The zinc oxalate structure has an elongated tetrahedral geometry, and its structure has two basic structures. The $\beta$-crystal belongs to the triclinic system, and each zinc ion forms the coordination with six oxygen atoms $\left(\mathrm{ZnO}_{6}\right)$. An octahedral configuration in which four of the six oxygen atoms coordinated to the zinc ion are from two oxalates, the other two are from water molecules, and the adjacent metal ions are connected by oxalate. The dimensional chain structure, the chains are connected by hydrogen bonding to form a threedimensional network structure. Zinc co-bonding forms an octahedral structure. The main bond is a hydrogen bond, and the chains are connected by a hydrogen bond to form a three-dimensional network structure. The $\beta$-crystal is bonded to the $\mathrm{Zn}-\mathrm{O}$ bond by an anion-cation chain $-\mathrm{C}_{2} \mathrm{O}_{4^{-}}$ $\mathrm{Zn}-\mathrm{C}_{2} \mathrm{O}_{4}-\mathrm{Zn}$, which is co-bonded with zinc to form an octahedral structure, which is the best position for the intercalation impurity.

Zinc oxalate has two different structures of $\beta$ - and $\beta$ zinc oxalate, and $\beta$ - zinc oxalate does not have the function of adsorbing hydrogen molecules. $\beta$-zinc oxalate becomes the main structure to interacting with hydrogen. The interacting molecules can be attracted to this Van der Waals force by $\beta$-zinc oxalate. $\beta$-zinc oxalate has the same ability with zinc oxide. The mixing ratio of RGO to $\mathrm{ZnO}$ to form $\mathrm{ZnC}_{2} \mathrm{O}_{4}$ is predictive of its hydrogen-sensing capabilities. The microstructure evolution of villous structures was characterized by X-ray diffraction and field emission scanning electron microscopy techniques. Gassensing experiments reveal response, recovery, and selectivity. The villous structures of $\mathrm{ZnC}_{2} \mathrm{O}_{4}$ can hydrogensensing at room temperature and an optimum operable temperature. The strong hydrogen response is attributed to the villous structure [5-7].

\section{Results}

The attractive force to hydrogen is the main issue. There are some keys could address this question. Here, we limit the review only to small molecules. Graphene is generally regarded as to have the function of adsorbing hydrogen molecules, but have the limit to wide-angle crystals. Zinc oxide has a function of adsorbing hydrogen molecules occurring a plane in the plane of $\left(001^{-}\right)$plane. $\beta$ - $\mathrm{ZnC}_{2} \mathrm{O}_{4}$ e becomes the main structure to interacting with hydrogen which has no crystal water in it.

\section{References}

1. Anand K, Singh O, Singh MP, Kaur J, Singh RC (2014) Hydrogen sensor based on graphene/ZnO nanocomposite Sensors and Actuators B: Chemical 195: 409-415.

2. Liu J, Guo C, Li CM, Li Y, Chi Q, et al. (2009) Carbondecorated ZnO nanowire array: A novel platform for direct electrochemistry of enzymes and biosensing applications. Electrochemistry Communications Surface Science 11(1): 202-205.

3. Wang JX, Sun XW, Yang Y, Huang H, Lee YC, et al. (2006) Hydrothermally grown oriented ZnO nanorod arrays for gas sensing applications. Nanotechnology 17(19): 037.

4. Vayssieres H, Keis K, Lindquist SE, Hagfeldt A (2001) Purpose Built Anisotropic Metal Oxide Material: 3D Highly Oriented Microrod Array of ZnO. J Phys Chem B 105(17): 3350-3352.

5. Hsu C, Hsu LA (2017) Fabrication and Characteristics of Villous Zinc Oxalate by using a Sol-Gel and Microbeam-Laser Method, Nanomed Nanotechnol 2(1): 000112.

6. Hsu C, Hsu LA (2018) Hydrogen Sensing with Villous Zinc Oxalate, Nanomed Nanotechnol 3(1): 000131.

7. Hsu C (2017) Features of phase-refined materials. Nanomed Nanotechnol 2(1): 000114. 